\title{
Cancer Research Network
}

National Cancer Institute

\section{Source}

National Cancer Institute. Cancer Research Network. NCI Thesaurus. Code C19720.

Ten major, non-profit managed care organizations that are members of the HMO Research Network will participate in the project, known as the Cancer Research Network. A key goal of the Cancer Research Network project is identifying the patient, treatment and delivery system factors that may make a difference in health outcomes for cancer. By combining the data capacities of these large integrated health systems, researchers will be able to study health care patterns among millions of patients who mirror the diversity of the nation in terms of age, gender, income, education, cultural background and location. 